\title{
Research on Engineering Undergraduates' Engineering Awareness
}

\author{
Yu Shi \\ College of Engineering and Technology \\ Tianjin Agricultural University \\ Tianjin, China \\ syych83@tjau.edu.cn
}

\author{
Chuanlin Li (Corresponding Author) \\ College of Engineering and Technology \\ Tianjin Agricultural University \\ Tianjin, China \\ 361473215@qq.com
}

\author{
Junrou Ji \\ College of Engineering and Technology \\ Tianjin Agricultural University \\ Tianjin, China \\ 95462845@qq.com \\ Hua Liu \\ College of Engineering and Technology \\ Tianjin Agricultural University \\ Tianjin, China \\ 41599386@qq.com
}

\begin{abstract}
Engineering awareness is one of the most important and basic quality of engineers. How to cultivate the engineering and technical personnel, which can be applied to the modern scientific theory and technology, and the engineering technology talents with modern engineering consciousness, it is a practical problem to be studied and solved urgently. Along with social progress, the method to improve the engineering awareness level for the engineering undergraduates put forward increasingly higher requirements. In order to meet the employment needs of engineering undergraduates for the enterprises, the members of Student Center for Innovation and Entrepreneurship of Tianjin Agricultural University have investigated and analyzed the data by visiting the undergraduates and the graduates working in related enterprises in Tianjin. The results showed that awareness of Engineering Undergraduates works through the learning activities in university as a whole. The elite training, engineering education reform should follow the guidelines of Tianjin Agricultural University in engineering and technology direction.
\end{abstract}

Keywords-Awareness; Engineering Education; Engineering Undergraduates; Innovative Quality

\section{INTRODUCTION}

With the advancement of technology and the needs of society, more and more people focus on training projects consciousness. Engineering Undergraduates in particular, whether it is social or internship candidates, as long as the relevant technology and engineering, some companies will assess engineering consciousness, in order to adapt to society, to adapt to the needs of engineering college, requiring higher engineering education reform engineering education to continue to consciousness.

Higher Engineering Education reform must focus on strengthening awareness training project of engineering undergraduates, allowing them to think for a variety of complex engineering problems, and enhance the ability of self-awareness, teamwork and communication skills, good professionalism, as well as comprehensive analysis and solutions ability to practical engineering problems, and inspire their innovation and entrepreneurial spirit, create a healthy personality, so that they become qualified senior engineering and technical personnel[1,2].

\section{NECESSITY OF STRENGTHENING ENGINEERING UNDERGRADUATES' ENGINEERING AWARENESS}

Engineering education as an important component of engineering education, is one of the weak points of higher engineering education today. In recent years, the undergraduates' difficult employment and hard to meet the needs of enterprises, social phenomena, many scholars and practitioners have conducted a special investigation and study and reach a consensus, arguing that colleges should pay attention to in cultivating talents education in college undergraduates' engineering awareness, as soon as possible after graduation to help make a smooth transition from campus to corporate culture and change from college student to employee's identity.

Quality work under majority Enterprise for graduates think: today's College graduates have a solid theoretical foundation, but lack of awareness of basic engineering, engineering work done by a lack of innovation, little knowledge of project implementation, in practice and it is difficult to use what they have learned to analyze and solve practical engineering problems, and so on.Businesses generally takes two years to train graduates to become a qualified engineering and technical personnel, which is the main causes of difficult employment of graduates in engineering colleges.

In Fig. 1, with the development of technology, interdisciplinary and the expansion of construction scale, engineering is becoming increasingly complex and requires comprehensive quality and ability of engineers and technicians,

1. Science Development Funds of Tianjin Agricultural University (2013S06);

2. Training Programs of Innovation and Entrepreneurship for Undergraduates (201410061033). 
both engineers with work experience and the undergraduates have no work experience must constantly improve engineering practical abilities and accumulate practical experience, thus raising project awareness.

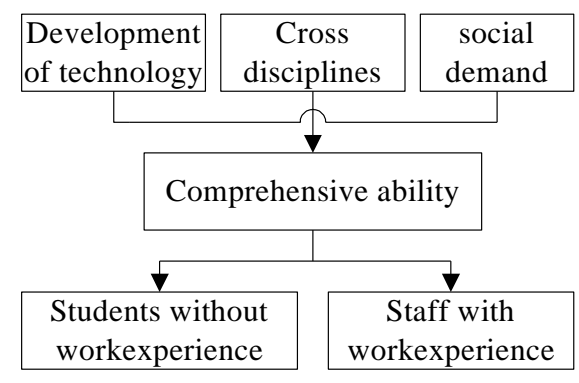

Fig. 1. Necessary of Comprehensive Ability

Therefore, it is urgent to change the traditional cultivation mode and concept in colleges of engineering, establish the consciousness of modern engineering, know background knowledge about the development and implementation of environmental, master the latest engineering knowledge and science and technology knowledge, to meet the needs of modern works to the modern engineers.

\section{INVESTIGATION OF ENGINEERING UNDERGRADUATES' ENGINEERING CONSCIOUSNESS}

In order to strengthen their awareness of engineering, effective engineering education improve undergraduates' learning engineering knowledge, cultivating the engineering practice ability of engineering practice, guiding undergraduates to consciously from the engineering point of view found, thinking, research and analysis to solve practical engineering problems, student Innovation Center in Tianjin agricultural college undergraduates and graduates, and related companies in a survey. The survey combined with practical engineering education, their awareness and training more indepth investigations and analysis.

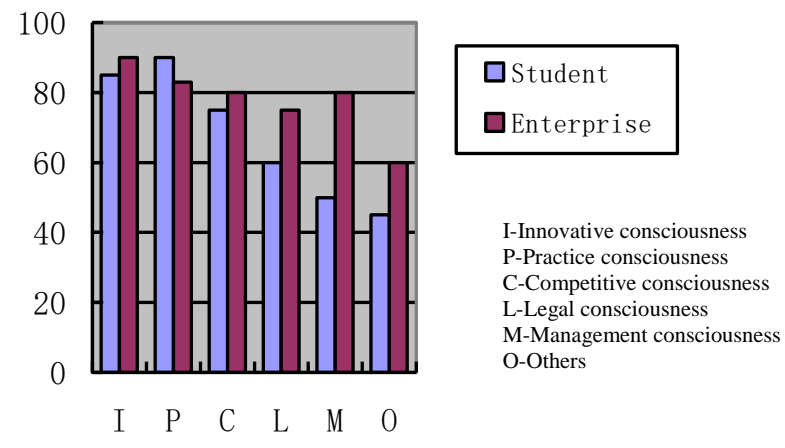

Fig. 2. Results of a Questionnaire Survey

Engineering sense refers to the creative consciousness, practice consciousness, awareness of competition, legal, management, and so on. According to survey results as shown in Fig. 2, undergraduates and enterprises attach importance to practice consciousness and sense of innovation, enterprises pay more attention to employee's awareness of innovation, at $90 \%$, and can be seen from the diagram, requirements for employees of enterprises is an all-round, comprehensive quality and ability. Firms are willing to take the time to train an employee, but also because seeing his potential. This potential ability is not one or two days can be formed, it needs to be a long-term process. At present, most engineering undergraduates' lack creativity, innovative spirit and creative thinking and innovative actions. And higher engineering education in China has long been focused only on book knowledge imparted; the undergraduates have little opportunity to participate directly in research training and engineering practices, assessment methods exam-oriented, resulting in undergraduates' knowledge structure, lack of creativity and innovative thinking. In order to change this situation, requirements engineering education should pay attention to cultivation of undergraduates' consciousness of innovation to inspire passion for innovation and creative thinking of undergraduates, engineering undergraduates receive knowledge from passive to active exploration and innovation, in the process of learning and practice, dares to ask new questions, new ideas, new rules, new ways to create new products, and new achievements.

Innovations in practice, practice makes perfect. Engineering education returning to practice is the common trend of engineering education in the world, and also the project of strengthening weak links. Undergraduates have high scientific and cultural qualities, but also to take advantage of opportunities and conditions, accepted engineering practice, in order to learn knowledge, accumulated experience and increase the ability improvement of practical ability and creative ability and the ability to use knowledge to solve realworld engineering problems 


\section{DEVELOPMENT AND IMPROVEMENT OF ENGINEERING UNDERGRADUATES’ ENGINEERING CONSCIOUSNESS}

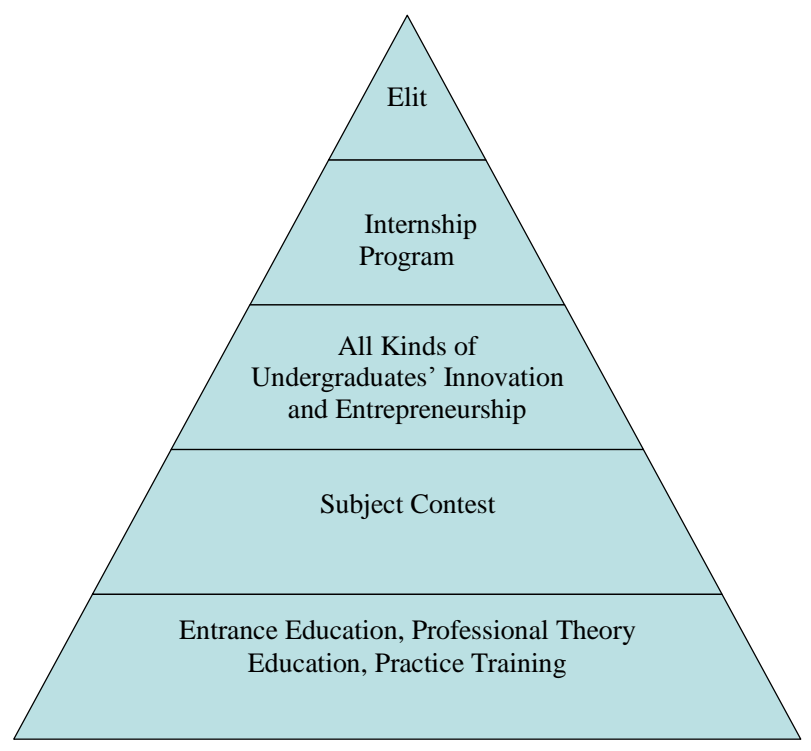

Fig. 3. Ways of Development and Improvement

Awareness training project is a systems engineering and gradual process, need to develop ways to guide through the school, specialized basic, practical training, colleges, enterprises, second class, cultural influence, etc., to achieve multi-level education in Fig. 3[3,4].

Awareness training project must run through the whole process of school education, college freshmen are generally from gate to gate, there is no practical experience, but also a lack of awareness of basic engineering, specializing in the field of work they are learning and future is also a lack of awareness and engage understanding. From the newly enrolled freshmen have to guide undergraduates to establish a correct sense of professional ideals, positive attitude and good engineering sense, can have a multiplier effect. Education and training and then specialized courses can enhance undergraduates' learning engineering theory; in order to improve undergraduates' interest and sense of participation, often outstanding alumni and seniors organizations and enterprises and technical personnel, undergraduates do lectures, exchange of experiences, pass on Tuition Solution confusion. To help them establish the correct professional thinking, enhance learning the professional pride and confidence.

By way of academic competitions and training colleges, enterprises, improve their sense of competition and practice awareness while promoting bottom out of the system so that more undergraduates involved. Allow undergraduates to learn in practice, practice in learning.

Academic competitions at all levels to enhance the undergraduates' awareness of innovation and responsibility, laid the foundation for the internship program, but also for engineering training offers the possibility, through continuous training and strengthening gradually cultivate engineering talent to become qualified enterprises employees, the core enterprise technologies.

\section{IMPROVEMENT OF THE UNDERGRADUATES' INNOVATIVE QUALITY}

In China, the number and scale of engineering University and Engineering Students are ranked in the world. Advanced engineering education has an important position and role in personnel training in universities. As the future creators of new productive society has undergone systems training, level of innovative quality of Engineering Students has a decisive role, which are not only closely related with international competitiveness in the field of engineering technology innovation but also for the industrialization and modernization construction to promote and achieve the goal of building an innovative country.

Innovative quality is an important concept. Quality is the sum of the relatively stable knowledge, ability and integrity and other factors, which formed and developed under the individual physiological basis in innate and acquired environment, teaching infertility and other factors. Innovative quality formed and developed which depended on the individual factors in innate and acquired physiological basis of environment, education, etc. It is the potential and showed relative stability knowledge, ability and character qualities or characteristics under the innovation process in practice. In educational practice, it is necessary to emphasize individual development potential, but also emphasizes the ability to nurture knowledge and character[5].

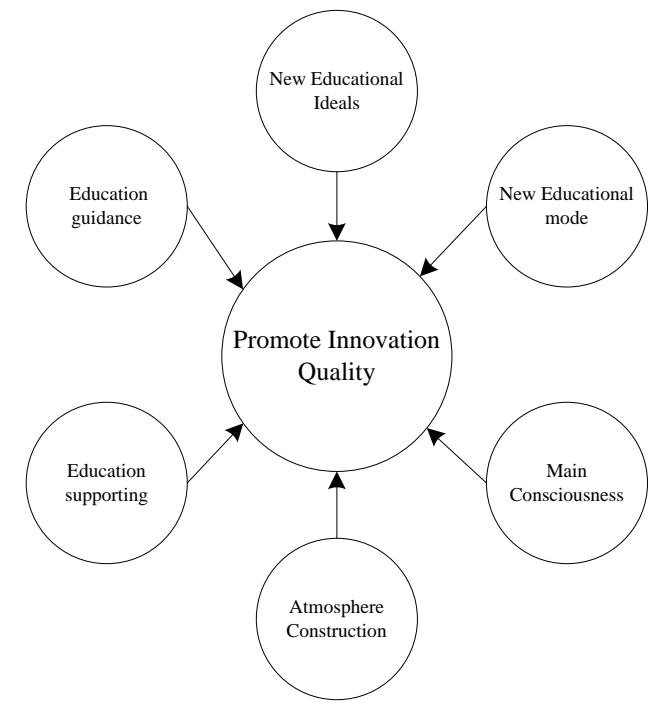

Fig.4. Improvement of the innovative quality

To promote the overall improvement of the innovative quality of engineering undergraduates, we should accurately grasp the impact of students' innovative quality development and upgrading of factors in accordance with the current status of innovative quality of engineering undergraduates by comprehensive measures[6]. 
These countermeasures include four points, as shown in Fig. 4. Firstly, vigorously promote to update the concept of higher engineering education and form new educational ideas in favor of improving innovative quality for undergraduates. Secondly, aims to build new educational mode to enhance the innovative quality including innovative training, curriculum design, teaching methods and evaluation mechanisms. Thirdly, increase resource security and the education supporting conditions. Efforts to strengthen the guidance of engineering college students, to build a platform, to organize activities and to provide support. Fourthly, to strengthen target of the education guidance for engineering students', different types of students applied differentiated innovation strategy to enhance the innovative quality. Fifthly, to create a suitable environment to enhance the innovative quality, strengthen the construction of campus culture, promote fusion between science and technology and humanities, and create innovation culture which could tolerate mistakes. Sixthly, stimulate engineering students' main consciousness for improving the innovative quality, to improve students' self- expectations to enhance innovative quality.

For students in their daily lives and leached in culture, it promotes the formation of students' cultural awareness, and thus the accumulation of normative guidelines have unique cultural heritage of Tianjin Agricultural University campus culture is prevailing in the university staff and students, the lifestyle, behavior patterns and value system is different from the university's important to identify other social organizations. University campus culture focus of humanistic spirit, a quiet and harmonious, healthy educational environment reflects the culture of a school, it can improve the overall quality of students play a subtle role. Therefore, strengthening the existing culture in personnel training, specific measures are as follows:

Carry out various distinctive forms of social practice. Clear that the party's education policy, education should be combined with productive labor and social practice. These are two basic ways to achieve the aims of education. It is a basic point of application-oriented university educational organization. Therefore, the construction of campus culture development application-oriented institutions requires us to apply what they learn to do, to join the practice. Through various channels, such as the establishment of a stable practice base outside school, to encourage students into the community, and vibrant through the organization of a second classroom activities to provide a stage for college students to apply their knowledge, students research awareness, innovative spirit and practical ability and to foster the application of innovative talents.

Strengthen the campus culture to create an environment of campus spiritual culture is the carrier of culture. It reflects the value orientation of college, aesthetic taste, carries historical University. Environmental Culture should distinguish the cultural construction of art, it is not the pursuit of fashion and unconventional, is not giving a strong visual impact, environmental and cultural construction should have a profound sense of pedagogy and cultural chemistry. First, do a good job leading the work culture. Use teaching building corridors, billboards and other cultural main building build environment, set up banners, signs and other famous celebrities boxes quotations publicity humanistic spirit, strong academic atmosphere, create a positive atmosphere of study and work. Secondly, appropriate set cultural landscape. Cultural landscape is set to reflect the civic ethics, professional ethics requirements, quality education, humanities training, improve students' sense of social responsibility. Cultural landscape setting can greatly increase the cultural heritage of the school. People text, to create a good cultural environment on campus, so that students in community activities, social practice during penetration humanistic spirit, promote the cultivation of students' humanistic quality, comprehensive development of college students play an important role.

Innovative entrepreneurship education is inseparable from highly qualified faculty. Professional settings, reform write textbooks and teaching methods, which are inseparable part of the active participation of the majority of teachers, we must continue to develop their entrepreneurial and innovative selection and outstanding teacher education. Universities should develop incentives to encourage potential young teachers directly involved in the practice of entrepreneurship and innovation, to encourage teachers to outside employment, government departments and corporate services, the combination of theory and practice toward higher levels. Teacher Sabbatical Leave implemented to encourage teachers after the completion of certain teaching and research mission, annual leave, special engage in academic research. Strengthen innovation and entrepreneurship in the field of international and domestic academic exchanges and seminars, demonstration teaching or research activities and innovative entrepreneurship education, in order to effectively improve the level of teachers' awareness of entrepreneurship and innovation. Additionally, it should put more foreign experts invited to the classroom, so that students have more contact with native speakers, to accept the influence of language environment and study abroad opportunities for a variety of new skills.

Through the implementation of the training mode, training part of the engineering capability and innovation capacity prominent student, led the class as a core interest in learning to play the "point, and the overall progress of" role[7]. While providing a better training model, guide the teaching work for training courses teaching and practice teaching.

\section{CONCLUSIONS}

Through Student Center for Innovation and Entrepreneurship of Tianjin Agricultural University undergraduates' surveys and related businesses, to understand the enterprise-level engineering undergraduates' awareness of the student's own understanding of the project, while strengthening the sense of direction and methods of engineering education reform provides for Tianjin Agricultural College.

\section{ACKNOWLEDGMENT}

This work was financially supported by the Science Development Funds of Tianjin Agricultural University 
(2013S06) and Training Programs of Innovation and Entrepreneurship for Undergraduates (201410061033).

\section{REFERENCES}

[1] Meng Zhao, Di Cui,Guicheng Wang. Training of Engineering Spirit in Engineering Education[A]. Information Engineering Research Institute,USA.Proceedings of 2013 3rd International Conference on Education and Education Management(EEM 2013) Information Engineering Research Institute,USA:Vol. 28, pp. 4,2013.

[2] Chunsheng Yu, Bei Yao, Qian Wang. Practice and experience of engineering culture development in the Sutong Bridge project. Engineering Sciences, 2009,01, pp. 87-92.

[3] Jin Wen, Junlin Xie, Mingzhong Li. Ways of Cultivating Engineering Students' Engineering Ability and Innovation Consciousness. Journa 1 of Higher Education in Science \& Technology. Vol. 28, pp. 116117,2009 .

[4] Borrego, Maura,Froyd, Jeffrey E,Hall, T Simin. Diffusion of Engineering Education Innovations: A Survey or Awareness and Adoption Rates in U.S. Engineering Departments. Journal of Engineering Education, 2010, pp. 993.

[5] Burton R, Clark, The Research Foundations of Graduate Education[M]. University of California Press,1993.

[6] Yue. X. D, Rudowicz. E. Perception of the most Creative Chinese by Undergraduates in Beijing, Guangzhou, Hong Kong and Taipei. Journal of Creative Behavior, 2002(36):89.

[7] Yanhui Hu. Employment ability oriented the significance of construction of practice teaching system in colleges and universities and the way [J]. Journal of going abroad and employment (job), 2011, 14:13-15. 